\title{
Multicomponent Fitness Training Improves Walking Economy in Older Adults
}

Citation for published version (APA):

Valenti, G., Bonomi, A. G., \& Westerterp, K. R. (2016). Multicomponent Fitness Training Improves Walking Economy in Older Adults. Medicine and Science in Sports and Exercise, 48(7), 1365-1370. https://doi.org/10.1249/MSS.0000000000000893

Document status and date:

Published: 01/07/2016

DOI:

10.1249/MSS.0000000000000893

Document Version:

Publisher's PDF, also known as Version of record

Document license:

Taverne

Please check the document version of this publication:

- A submitted manuscript is the version of the article upon submission and before peer-review. There can be important differences between the submitted version and the official published version of record.

People interested in the research are advised to contact the author for the final version of the publication, or visit the DOI to the publisher's website.

- The final author version and the galley proof are versions of the publication after peer review.

- The final published version features the final layout of the paper including the volume, issue and page numbers.

Link to publication

\footnotetext{
General rights rights.

- You may freely distribute the URL identifying the publication in the public portal. please follow below link for the End User Agreement:

www.umlib.nl/taverne-license

Take down policy

If you believe that this document breaches copyright please contact us at:

repository@maastrichtuniversity.nl

providing details and we will investigate your claim.
}

Copyright and moral rights for the publications made accessible in the public portal are retained by the authors and/or other copyright owners and it is a condition of accessing publications that users recognise and abide by the legal requirements associated with these

- Users may download and print one copy of any publication from the public portal for the purpose of private study or research.

- You may not further distribute the material or use it for any profit-making activity or commercial gain

If the publication is distributed under the terms of Article $25 \mathrm{fa}$ of the Dutch Copyright Act, indicated by the "Taverne" license above, 


\title{
Multicomponent Fitness Training Improves Walking Economy in Older Adults
}

\author{
GIULIO VALENTI ${ }^{1}$, ALBERTO GIOVANNI BONOMI $^{2}$, and KLAAS ROELOF WESTERTERP ${ }^{1}$ \\ ${ }^{1}$ Department of Human Biology, Maastricht University, Maastricht, THE NETHERLANDS; and ${ }^{2}$ Personal Health Solutions, \\ Philips Research Laboratories, Eindhoven, THE NETHERLANDS
}

\begin{abstract}
VALENTI, G., A. G. BONOMI, and K. R. WESTERTERP. Multicomponent Fitness Training Improves Walking Economy in Older Adults. Med. Sci. Sports Exerc., Vol. 48, No. 7, pp. 1365-1370, 2016. Background: Walking economy declines with increasing age, possibly leading to mobility limitation in older adults. Multicomponent fitness training could delay the decline in walking economy. Purpose: This study aimed to determine the effect of multicomponent fitness training on walking economy in older adults. Methods: Participants were untrained adults, age 50 to $83 \mathrm{yr}\left(N=26,10\right.$ males, age $=63 \pm 6 \mathrm{yr}, \mathrm{BMI}=25.6 \pm 2.1 \mathrm{~kg} \cdot \mathrm{m}^{-2}$, mean $\left.\pm \mathrm{SD}\right)$. A control group was also recruited $\left(N=16,9\right.$ males, age $\left.=66 \pm 10 \mathrm{yr}, \mathrm{BMI}=25.4 \pm 3.0 \mathrm{~kg} \cdot \mathrm{m}^{-2}\right)$, matching the intervention group for age, weight, body composition, and fitness. The intervention group followed a multicomponent fitness program of $1 \mathrm{~h}$, twice per week during $1 \mathrm{yr}$. The control group did not take part in any physical training. Fat-free mass, walking economy, and maximal oxygen uptake $\left(\dot{\mathrm{VO}}_{2 \max }\right)$ were measured in both groups before and after the year. Walking economy was measured with indirect calorimetry as the lowest energy needed to displace $1 \mathrm{~kg}$ of body mass for $1 \mathrm{~m}$ while walking on a treadmill. The data were compared between the two groups with repeated-measures ANOVA. Results: Thirty-two subjects completed all measurements. There was an interaction between the effects of time and group on $\dot{\mathrm{VO}}_{2 \max }(P<0.05)$ and walking economy $(P<0.05)$, whereas fat-free mass did not change significantly $(P=0.06)$. $\dot{\mathrm{V}}{ }_{2 \max }$ decreased by $1.8 \mathrm{~mL} \cdot \mathrm{kg}^{-1} \cdot \mathrm{min}^{-1}$ in the control group and increased by $1.3 \mathrm{~mL} \cdot \mathrm{kg}^{-1} \cdot \mathrm{min}^{-1}$ in the intervention group. The lowest energy needed to walk increased by $0.12 \mathrm{~J} \cdot \mathrm{kg}^{-1} \cdot \mathrm{m}^{-1}$ in the control group and decreased in the intervention group by $0.13 \mathrm{~J} \cdot \mathrm{kg}^{-1} \cdot \mathrm{m}^{-1}$. Conclusion: Multicomponent fitness training decreases walking cost in older adults, preserving walking economy. Thus, training programs could delay mobility limitation with increasing age. Key Words: ENERGY EXPENDITURE, COST OF WALKING, AEROBIC CAPACITY, AGING, PHYSICAL ACTIVITY INTERVENTION
\end{abstract}

1 ging is associated with reduced physical activity $(42,51)$ and loss of independent functioning (4). Low physical activity in older adults is due to multiple factors such as increased fatigue, reduced energy reserve $(22,40)$, decreased maximal aerobic capacity (12), and increased energetic cost of daily life activities (39). Increased cost of daily life activities results in lower energy reserve $(27,48)$, which possibly undermines independent functioning. Delaying the increase in cost of daily life activities would induce higher energy reserve, likely prolonging independent functioning in older adults.

Walking represents the most frequent daily life activity, and it allows individuals to carry out simple and fundamental tasks (23). Measures of walking ability such as walking speed have been designated as functional vital sign

Address for correspondence: Giulio Valenti, M.Sc., Department of Human Biology, Maastricht University, PO Box 616, 6200 MD, Maastricht, The Netherlands; E-mail: g.valenti@maastrichtuniversity.nl.

Submitted for publication September 2015.

Accepted for publication January 2016.

0195-9131/16/4807-1365/0

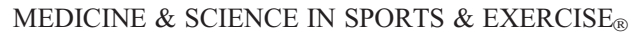

Copyright $\left({ }^{\circ} 2016\right.$ by the American College of Sports Medicine

DOI: 10.1249/MSS.0000000000000893
(28). Higher walking speed at older age indicates preserved functional and health status and it is related to lower death rates (1). Older adults with low walking speed tend to show higher walking cost, requiring more energy to displace $1 \mathrm{~kg}$ of body mass for $1 \mathrm{~m}$ while walking (49).

Walking cost, assessed as total energy expenditure during walking minus standing energy expenditure divided by distance and body mass (27), follows a U-shaped relation with walking speed with a minimum between 0.9 and $1.4 \mathrm{~m} \cdot \mathrm{s}^{-1}$ (27). The walking speed at which the minimum is measured approximates subjects' preferred walking speed and is therefore the condition that best represents daily life conditions $(5,35)$. The minimum walking cost increases gradually after the 50th year of age, possibly leading to reduced mobility in older adults $(21,24,38)$.

Several factors have been suggested to contribute to the age-related decline in walking economy, such as strength, sarcopenia, loss of neuromuscular coordination, and decreased regularity of walking patterns. Sarcopenia leads to a decline in muscle strength and power. Augmenting muscle power to contrast the decline in muscle strength during walking can decrease walking cost and increase preferred walking speed (30). At the same time, the age-related decline in neuromuscular coordination can alter the pattern of recruitment of muscles and the timing of limb movements, 
inducing compensatory strategies requiring increased energy (47). Furthermore, irregular body acceleration in the horizontal plane is associated with increased walking cost (45). Interventions that address these aforementioned factors could indirectly reduce the cost of walking. Fitness training might be an effective strategy to reach these effects.

Fitness training is generally divided in three categories, all of which could indirectly improve walking economy. Resistance training can counteract sarcopenia (36), which naturally occurs with aging (37), by increasing muscle mass, strength (29), and stability (9) and thus decrease walking cost (14). Stretching exercises improve flexibility, joint range of motion, and proprioception with consequent effects on balance and stability $(11,19)$, which might result in reduced walking cost. Endurance training aims at improving cardiovascular conditioning and results in increased maximal oxygen uptake as well as reduced recovery time $(13,16)$. After an endurance-training program, individuals showed decreased HR (25) and energy expenditure during exercise (50). Multicomponent fitness training is a combination of resistance stretching and endurance training $(18,33)$, and it might incorporate the benefits of these training categories, resulting in improved walking economy.

Given the importance of delaying the age-related decline in walking economy to maintain independence and quality of life and to mitigate health risks in older adults, this study aimed at determining the effect of $1 \mathrm{yr}$ multicomponent fitness training on walking economy in older adults.

\section{METHODS}

Population. Untrained adults, age 50 to $83 \mathrm{yr}(N=26$, 10 males, age $=63 \pm 6 \mathrm{yr}, \mathrm{BMI}=25.6 \pm 2.1 \mathrm{~kg} \cdot \mathrm{m}^{-2}$, mean \pm $\mathrm{SD})$ were recruited for the fitness training through advertisements in local newspapers. A control group $(N=16,9$ males, age $=66 \pm 10 \mathrm{yr}, \mathrm{BMI}=25.4 \pm 3.0 \mathrm{~kg} \cdot \mathrm{m}^{-2}$ ) was recruited similarly matching for age, weight, body composition, and fitness level. Subjects of both groups signed a written informed consent and subsequently completed and discussed with a medical doctor a questionnaire covering orthopedic conditions, neurological disorders, and cardiovascular problems that could affect the study. All subjects were in good orthopedic, neurological, and cardiovascular conditions. The study was conducted according to the Declaration of Helsinki, and the Ethics Committee of the Maastricht University Medical Center approved the study. This trial was registered at www.clinicaltrials.gov as NCT01609764.

Study design. Body mass, fat-free mass, walking economy, and maximal oxygen uptake normalized for body mass $\left(\dot{\mathrm{V}}_{2 \max }\right)$ were measured at baseline and after 1 yr. During this year, the intervention group followed a fitness program, whereas the control group was not enrolled in any fitness training and maintained the habitual physical routine.

Body composition. Body mass was measured with subjects in underwear after an overnight fast on an electronic scale (Life Measurement Corporation Inc., Concord, CA) to the nearest $0.01 \mathrm{~kg}$.
Fat-free mass was derived from body mass and total body water using the deuterium dilution method as described in the Maastricht protocol (53).

Walking economy. Walking economy was measured as lowest energy needed to displace $1 \mathrm{~kg}$ of body mass for $1 \mathrm{~m}$ while walking on a treadmill. Subjects walked on a treadmill at four speeds while wearing a mask to measure energy expenditure, following a previously described protocol (45). Briefly, subjects started with 5 min standing followed by walking at $0.83 \mathrm{~m} \cdot \mathrm{s}^{-1}$. Walking speed was increased every $5 \mathrm{~min}$ by $0.28 \mathrm{~m} \cdot \mathrm{s}^{-1}$. If the subject was able to walk at four speeds up to $1.67 \mathrm{~m} \cdot \mathrm{s}^{-1}$ without running, the test ended; otherwise, the test was continued at $0.56 \mathrm{~m} \cdot \mathrm{s}^{-1}$ to obtain four speeds at regular intervals for each subject. Oxygen consumption and carbon dioxide production were measured with an indirect calorimeter (Omnical; Maastricht Instruments, Maastricht, The Netherlands). The calorimeter has an automatic (30-min cycle) calibration system using certified span gas (1\% certificate) and zero gas (N2 at $99.999 \%$ purity). The accuracy of the output data was verified weekly with a methanol-burning test as previously recommended for similar systems (2). The calculation of total energy expenditure from $\mathrm{O}_{2}$ consumption and $\mathrm{CO}_{2}$ production was based on Brouwer's formula (8). Total energy expenditure was averaged over the plateau during the last 2 min of standing and of each walking speed. Walking cost was defined as the energy needed to displace $1 \mathrm{~kg}$ of body mass for $1 \mathrm{~m}$ while walking, and it was calculated as total energy expenditure minus standing energy expenditure, normalized for walking distance and for body mass. The minimum walking cost $\left(\right.$ WCost $_{\mathrm{min}}, \mathrm{J} \cdot \mathrm{kg}^{-1} \cdot \mathrm{m}^{-1}$ ) was considered for further analysis.

Maximal oxygen uptake. Maximal oxygen uptake was measured after an incremental protocol (20). To guarantee the independence of the measure from walking economy, the test was performed on a cycle ergometer. Furthermore, the use of a cycle ergometer is safer for older subjects compared with a treadmill $(3,17)$. A warming up workload of $75 \mathrm{~W}$ for men and $50 \mathrm{~W}$ for women was maintained for $5 \mathrm{~min}$ and then increased by $50 \mathrm{~W}$ every $2.5 \mathrm{~min}$. The increase in workload was reduced to $25 \mathrm{~W}$ when the respiratory quotient was higher than one or when HR reached a value of $35 \mathrm{bpm}$ less than the age-predicted maximal HR (220 bpm - age). The test continued until exhaustion. A mask covering mouth and nose was used to collect expired air, which was continuously analyzed for $\mathrm{O}_{2}$ consumption and $\mathrm{CO}_{2}$ production (Omnical, Maastricht Instruments).

Intervention. The intervention group followed a group fitness program of $1 \mathrm{~h}$, at least two times per week during $1 \mathrm{yr}$, available at a local fitness center. Classes of the program were held in the morning from Monday until Thursday. Subjects were asked to participate on two nonconsecutive days every week. Subjects were allowed to miss at most $10 \%$ of the lessons along the year, allowing a cumulative $5 \mathrm{wk}$ of holidays or sickness during the 1-yr study. The fitness instructor who coached every class designed the program specifically for 


\begin{tabular}{|c|c|c|c|c|}
\hline & \multicolumn{2}{|c|}{ Control } & \multicolumn{2}{|c|}{ Intervention } \\
\hline & \multicolumn{2}{|c|}{ Gender $(M=6 / F=4)$} & \multicolumn{2}{|c|}{ Gender $(M=9 / F=13)$} \\
\hline & Month 0 & Month 12 & Month 0 & Month 12 \\
\hline Body mass (kg) & $72.1 \pm 14.8$ & $73.6 \pm 17.1$ & $73.9 \pm 10.8$ & $74.1 \pm 10.4$ \\
\hline FFM $(\mathrm{kg})$ & $51.2 \pm 12.2$ & $51.3 \pm 12.5$ & $50.5 \pm 9.0$ & $52.3 \pm 9.8^{\star}$ \\
\hline $\mathrm{BMI}\left(\mathrm{kg} \cdot \mathrm{m}^{-2}\right)$ & $24.8 \pm 3.2$ & $25.2 \pm 3.9$ & $25.6 \pm 2.1$ & $25.7 \pm 2.2$ \\
\hline$\dot{\mathrm{V}} \mathrm{O}_{2 \max }\left(\mathrm{L} \cdot \mathrm{min}^{-1}\right)$ & $2.19 \pm 0.78$ & $2.07 \pm 0.63$ & $2.04 \pm 0.50$ & $2.15 \pm 0.52 \dagger$ \\
\hline$\dot{\mathrm{V}} \mathrm{O}_{2 \mathrm{max}} /$ body mass $\left(\mathrm{mL} \cdot \mathrm{kg}^{-1} \cdot \mathrm{min}^{-1}\right)$ & $30.1 \pm 8.7$ & $28.2 \pm 7.5$ & $27.6 \pm 4.9$ & $28.9 \pm 4.9 \dagger$ \\
\hline Absolute walking cost $\left(\mathrm{J} \cdot \mathrm{m}^{-1}\right)$ & $174 \pm 37$ & $186 \pm 58$ & $176 \pm 31$ & $167 \pm 26 \dagger$ \\
\hline Walking cost $\left(\mathrm{J} \cdot \mathrm{kg}^{-1} \cdot \mathrm{m}^{-1}\right)$ & $2.47 \pm 0.58$ & $2.59 \pm 0.85$ & $2.39 \pm 0.35$ & $2.26 \pm 0.28 \dagger$ \\
\hline
\end{tabular}

FFM, fat-free mass; walking cost, the lowest energy needed to displace $1 \mathrm{~kg}$ of body mass for $1 \mathrm{~m}$ while walking.

*Significant time effect $(P<0.05)$.

†Significant group-time effect $(P<0.05)$.

participants older than $50 \mathrm{yr}$. Each class started with a warming up of 15 min during which participants performed moderate intensity free-body aerobic exercises accompanied by music. Subsequently, subjects exercised for $30 \mathrm{~min}$ in a resistance circuit training of moderate intensity using weight stack machines. Three sets of 15 repetitions were performed of the following exercises: chest press, lateral row, pull down, triceps extension, biceps curl, leg press, leg curl, and abdominal crunch. Each class ended with 15 min of cooling down, including core, stretching, and balance exercises of low intensity, accompanied by music. The instructor supervised all subjects, assessing their participation and promoting a progressive increase of the training load. A researcher visited periodically the fitness center during hours of class to motivate subjects and to collect feedback from the instructor about participation and training progress. Subjects participating in less than two sessions per week were contacted and motivated to resume regular participation in the program.

Data analysis. The data were compared between the two groups with two-way repeated-measures ANOVA with two factors (time and group) and two levels per factor (month 0 -month 12, intervention-control). The number of levels assured that the assumption on the sphericity of the data was verified. Post hoc analysis was not considered because the number of levels of both factors was only two. All variables were expressed as mean $\pm \mathrm{SD}$. The statistical significance threshold was set at $P<0.05$.

\section{RESULTS}

Six (three males) of 16 control subjects dropped out during the study and were excluded from the analysis. Four (one male) of 26 intervention subjects were excluded from the study because of insufficient adherence to the intervention. Thirty-two subjects completed all measurements. Males and females did not differ in age, optimal speed or WCost $_{\text {min }}$, and were analyzed together. Subject characteristics at baseline did not differ between groups (Table 1).

Four subjects could not walk at $1.67 \mathrm{~m} \cdot \mathrm{s}^{-1}$ and walked at $0.56 \mathrm{~m} \cdot \mathrm{s}^{-1}$ to obtain four speeds at regular intervals for each subject. The optimal walking speed, i.e., the walking speed with the lowest walking cost, at baseline was $1.18 \pm 0.16 \mathrm{~m} \cdot \mathrm{s}^{-1}$ and was not significantly different between groups. The relationship between walking cost and speed at baseline is presented in Figure 1.

There was a statistically significant interaction between the effects of time and group on $\dot{\mathrm{V}} \mathrm{O}_{2 \max }(P<0.05)$ and walking economy $(P<0.05)$. $\dot{\mathrm{VO}}_{2 \max }$ increased in the intervention

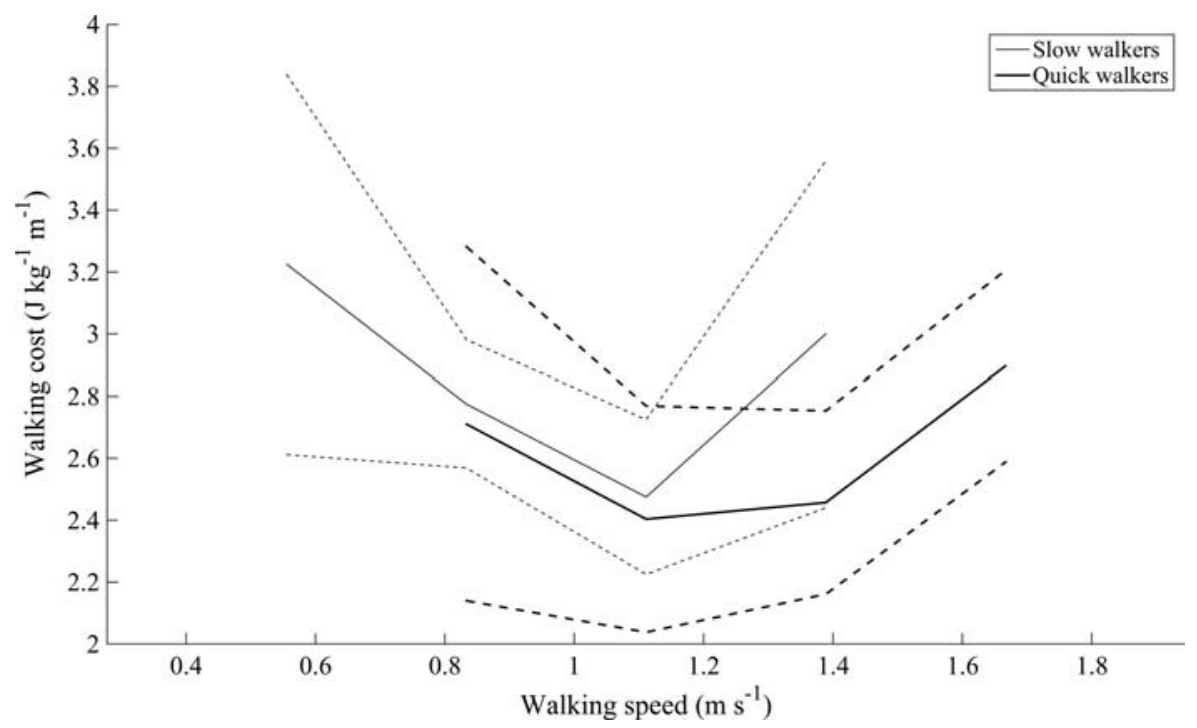

FIGURE 1-Relationship between walking cost and speed at baseline. Subjects walked at regular speed intervals between $0.56 \mathrm{~m} \cdot \mathrm{s}^{-1}$ and $1.39 \mathrm{~m} \cdot \mathrm{s}^{-1}$ (slow walkers, $N=4$ ) or between $0.83 \mathrm{~m} \cdot \mathrm{s}^{-1}$ and $1.67 \mathrm{~m} \cdot \mathrm{s}^{-1}$ (quick walkers, $N=28$ ). Solid lines represent mean values, and dashed lines represent SD values. 
group by $1.3 \mathrm{~mL} \cdot \mathrm{kg}^{-1} \cdot \mathrm{min}^{-1}$ and decreased in the control group by $1.8 \mathrm{~mL} \cdot \mathrm{kg}^{-1} \cdot \mathrm{min}^{-1}$ (Table 1). The cost of walking increased in the control group along the year by $0.12 \mathrm{~J} \cdot \mathrm{kg}^{-1} \cdot \mathrm{m}^{-1}$, which was approximately $5 \%$ of the initial cost of walking. Subjects who followed the fitness training showed the opposite tendency, with a reduction of the cost of walking of $0.13 \mathrm{~J} \cdot \mathrm{kg}^{-1} \cdot \mathrm{m}^{-1}$, which was more than $5 \%$ of the initial cost of walking and resulted in a 13\% lower waking cost than the control group (Fig. 2). Total body mass was maintained stable during the study. Fat-free mass had the tendency to increase in the intervention group, although the time-group interaction did not reach significance $(P=0.06)$.

\section{DISCUSSION}

The results of the study showed that, after 1-yr of multicomponent fitness training, the energetic cost of walking in older adults decreased significantly compared with a control group. The training increased $\dot{\mathrm{VO}}_{2 \max }$, improving the aerobic capacity of trained older adults compared with the decline shown by a control group. Less energy needed for walking might promote sustained physical activity and contribute to prolong the independence of trained older adults from external aid for daily life activity.

Approximately $85 \%$ of the subjects recruited for the intervention complied with the intervention, whereas $63 \%$ of the control subjects completed the study. Previous studies, including $1 \mathrm{yr}$ fitness training interventions, reported compliances of approximately $50 \%(10,41)$. One explanation for the higher compliance in the current study might be the average good health of the subjects, with an average $\dot{\mathrm{VO}}_{2 \max }$ of $27.6 \pm 4.9 \mathrm{~mL} \cdot \mathrm{kg}^{-1} \cdot \mathrm{min}^{-1}$ at baseline and a BMI of $25.7 \pm$ $2.5 \mathrm{~kg} \cdot \mathrm{m}^{-2}$ (34). Healthy individuals are likely to perceive the benefits of an active lifestyle and this might have contributed to the high compliance to the training. Other possible explanations for the higher compliance are the initial motivation of subjects and the social aspect of a group fitness program. Most of the intervention subjects were motivated by the opportunity to engage in some physical activity. Many of them referred that being part of a study gave them an external motivation and helped them maintaining their fitness routine. Participation was possibly also promoted by the fact that the training was financed by the university and had no economical effect on the subjects. At the end of the study, most of the intervention subjects expressed the intention to continue independently the fitness training at the fitness center. The factors that influenced this decision were the stimulating environment provided by a group lesson and the purpose of preserving the physiological benefits acquired during the year of fitness. This intention is compatible with previous studies where the majority of subjects were still training $4 \mathrm{yr}$ after study participation (43).

Body mass was preserved during the study. Some studies showed that fitness training might induce weight loss by increasing exercise induced energy expenditure, but the amount of weight loss seems to be lower than predicted (52). Possible explanations are a compensatory increase in energy intake or a reduction of nonexercise energy expenditure (44). In this study, changes in body mass would have created a potential confounding factor, and therefore no dietary indications were given to the subjects. As a result, subjects remained weight stable during the study. Although body mass remained constant, fat-free mass had the tendency to increase in the intervention group, but significance was not reached $(P=0.06)$. The increase in fat-free mass was nonsignificant, possibly because the fitness training was of moderate intensity as previously shown in a similar multicomponent fitness training of moderate intensity (25).

$\dot{\mathrm{V}} \mathrm{O}_{2 \max }$ increased by $1.3 \mathrm{~mL} \cdot \mathrm{kg}^{-1} \cdot \mathrm{min}^{-1}$ in the training group, whereas it declined by $1.8 \mathrm{~mL} \cdot \mathrm{kg}^{-1} \cdot \mathrm{min}^{-1}$ in the control group. The increase confirms previous studies showing
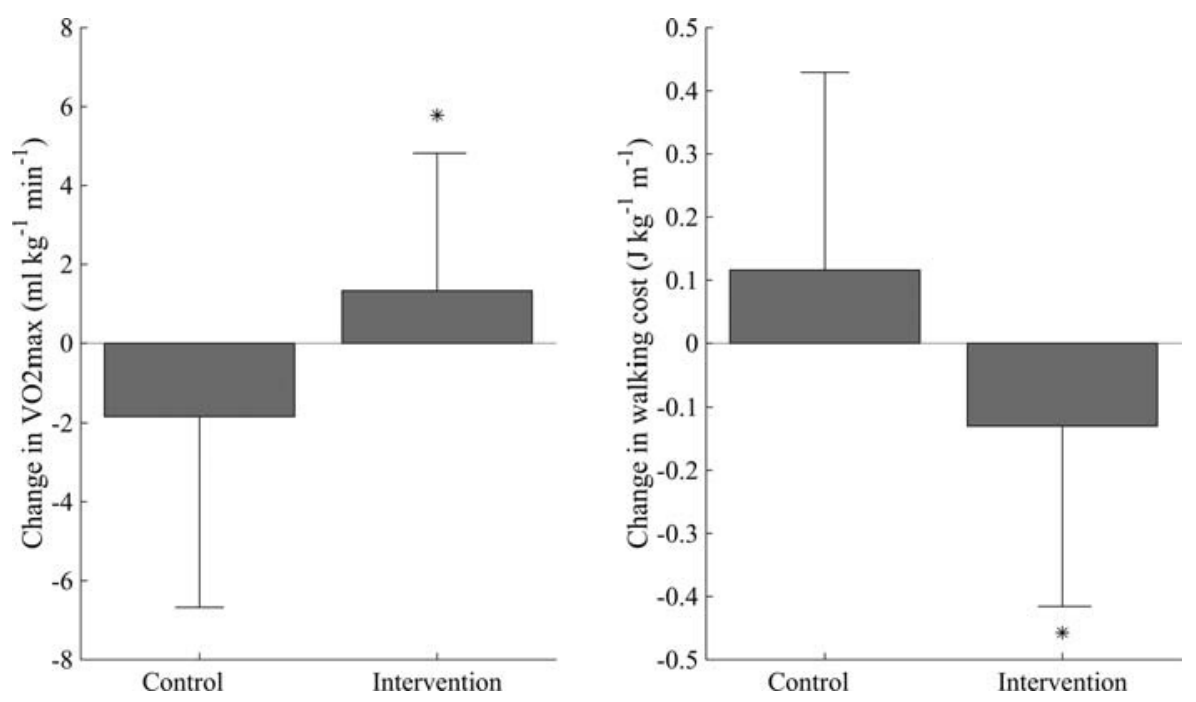

FIGURE 2-Comparison of the change in maximal oxygen uptake $\left(\dot{\mathrm{V}} \mathrm{O}_{2 \max }\right)$ and walking cost for 1 yr between a control group $(N=10)$ and an intervention group $(N=22)$. The whiskers represent $\mathrm{SD}$. $* P<0.05$, two-way repeated-measures ANOVA of the interaction between the effects of time and group. 
that fitness training improves aerobic capacity (43). Although one main determinant of $\dot{\mathrm{VO}}_{2 \max }$ is body mass, the effect of fitness training remained significant when presented in absolute terms $\left(\mathrm{L} \cdot \mathrm{min}^{-1}\right)$. The training, and especially its endurance component, might have increased $\dot{\mathrm{VO}}_{2 \max }$ by acting on multiple physiological factors, which determine the agerelated decline in $\dot{\mathrm{V}}_{2 \max }$. These factors include increased cardiac output, improved oxygen delivery to the muscle, and increased oxidative capacity of skeletal muscles (6). The observed increase in aerobic capacity indicates a good compliance to the intervention.

The cost of walking decreased by $0.13 \pm 0.29 \mathrm{~J} \cdot \mathrm{kg}^{-1} \cdot \mathrm{m}^{-1}$ in the intervention group compared with the control group in which the cost of walking increased by $0.12 \pm$ $0.31 \mathrm{~J} \cdot \mathrm{kg}^{-1} \cdot \mathrm{m}^{-1}$. A baseline cost of walking of approximately $2.4 \mathrm{~J} \cdot \mathrm{kg}^{-1} \cdot \mathrm{m}^{-1}$ is in line with the cost of walking reported in previous studies $(31,32,45)$. One study has reported no changes in walking economy in older adults after a similar intervention (26). In that study, the minimum cost of walking was around $0.15 \mathrm{~mL} \mathrm{O} \mathrm{O}_{2} \cdot \mathrm{kg}^{-1} \cdot \mathrm{m}^{-1}$. Assuming a conversion factor of $20.3 \mathrm{~J} \cdot \mathrm{mL}^{-1} \mathrm{O}_{2}$ for a regular diet and (54), the minimum cost of walking in that study can be estimated at $3.05 \mathrm{~J} \cdot \mathrm{kg}^{-1} \cdot \mathrm{m}^{-1}$, a very high value possibly indicating measurement bias. The results from the current study were in line with previous literature and indicate that multicomponent fitness training might delay the age-related decline in walking economy.

Increased metabolic efficiency during exercise might partly explain the effect of training on the metabolic cost of walking. Endurance training can influence subjects metabolism by decreasing energy expenditure during exercise (50). Possible mechanisms include increased oxygen extraction and increased oxidative capacity of skeletal muscles. These physiological adaptations have been shown after enrollment in exercise training in patients with chronic heart failure, and they might also contribute to increased aerobic capacity (15). Other types of training such as task-specific motor learning interventions have been shown to be effective in improving

\section{REFERENCES}

1. Abellan van Kan G, Rolland Y, Andrieu S, et al. Gait speed at usual pace as a predictor of adverse outcomes in community-dwelling older people an International Academy on Nutrition and Aging (IANA) Task Force. J Nutr Health Aging. 2009;13(10):881-9.

2. Adriaens MP, Schoffelen PF, Westerterp KR. Intra-individual variation of basal metabolic rate and the influence of daily habitual physical activity before testing. Br J Nutr. 2003;90(2): 419-23.

3. Astrand PO. Measurement of maximal aerobic capacity. Can Med Assoc J. 1967;96(12):732-5.

4. Bajekal M, Wheller L, Dix D. Estimating residents and staff in communal establishments from the 2001 Census. Health Stat $Q$. 2006;31:42-50.

5. Bastien GJ, Willems PA, Schepens B, Heglund NC. Effect of load and speed on the energetic cost of human walking. Eur J Appl Physiol. 2005;94(1-2):76-83.

6. Betik AC, Hepple RT. Determinants of $\dot{\mathrm{VO}}_{2 \max }$ decline with aging: an integrated perspective. Appl Physiol Nutr Metab. 2008; 33(1):130-40. motor control (7), with direct improvements in walking cost (46). Task-specific interventions have relevant effects on walking economy, but their effect on aerobic capacity is not significant. The current study instead involved a multicomponent fitness training and showed a significant effect both on walking economy and on aerobic capacity, which results in an increased energy reserve and is thought to have a positive influence on independence and quality of life (49).

Future studies could focus on the effect of multicomponent fitness training on independence and quality of life. The results of this study suggest that quality of life in trained older adults might have improved, but no direct measures of quality of life were taken. Follow-up studies could assess whether the beneficial effect of multicomponent fitness training is maintained when the training is interrupted. It is also possible that a larger population or a longer period of training could reveal smaller but relevant consequences of multicomponent fitness training, such as the trend shown for the fat-free mass in this study.

In conclusion, multicomponent fitness training improved aerobic capacity and decreased the metabolic cost of walking. Less energy needed for walking might promote sustained physical activity and contribute to prolong the independence of trained older adults from external aid for daily life activities.

Special thanks are due to all participants for their time and commitment to the study.

The research was funded by Maastricht University. Authors do not declare any conflict of interest. The results of the present study do not constitute endorsement by the American College of Sports Medicine.

K. R. Westerterp and G. Valenti designed the study. G. Valenti collected the data, analyzed the data, and wrote the manuscript. K. R. Westerterp and A. G. Bonomi contributed to the interpretation of the data and reviewed the manuscript. The study was executed under the supervision of K. R. Westerterp. Everyone who contributed significantly to the work has been listed, and all authors read and approved the final manuscript.

7. Brach JS, Lowry K, Perera S, et al. Improving motor control in walking: a randomized clinical trial in older adults with subclinical walking difficulty. Arch Phys Med Rehabil. 2015;96(3):388-94.

8. Brouwer E. On simple formulae for calculating the heat expenditure and the quantities of carbohydrate and fat oxidized in metabolism of men and animals, from gaseous exchange (oxygen intake and carbonic acid output) and urine-N. Acta Physiol Pharmacol Neerl. 1957;6:795-802.

9. Chen MS, Jiang BC. Resistance training exercise program for intervention to enhance gait function in elderly chronically ill patients: multivariate multiscale entropy for center of pressure signal analysis. Comput Math Methods Med. 2014;2014:471356. DOI: $10.1155 / 2014 / 471356$.

10. Cowper PA, Morey MC, Bearon LB, et al. The impact of supervised exercise on the psychological well-being and health status of older veterans. J Appl Gerontol. 1991;10(4):469-85.

11. Farinatti PT, Rubini EC, Silva EB, Vanfraechem JH. Flexibility of the elderly after one-year practice of yoga and calisthenics. Int $J$ Yoga Therap. 2014;24:71-7. 
12. Fleg JL, Morrell CH, Bos AG, et al. Accelerated longitudinal decline of aerobic capacity in healthy older adults. Circulation. 2005; 112(5):674-82.

13. Grey TM, Spencer MD, Belfry GR, Kowalchuk JM, Paterson DH, Murias JM. Effects of age and long-term endurance training on $\dot{\mathrm{VO}}_{2}$ kinetics. Med Sci Sports Exerc. 2015;47(2):289-98.

14. Heggelund J, Morken G, Helgerud J, Nilsberg GE, Hoff J. Therapeutic effects of maximal strength training on walking efficiency in patients with schizophrenia - a pilot study. BMC Res Notes. 2012;5:344.

15. Hirai DM, Musch TI, Poole DC. Exercise training in chronic heart failure: improving skeletal muscle $\mathrm{O}_{2}$ transport and utilization. $\mathrm{Am}$ J Physiol Heart Circ Physiol. 2015;309(9):H1419-39.

16. Huang G, Wang R, Chen P, Huang SC, Donnelly JE, Mehlferber JP. Dose-response relationship of cardiorespiratory fitness adaptation to controlled endurance training in sedentary older adults. Eur J Prev Cardiol. 2016;23(5):518-29.

17. Huggett DL, Connelly DM, Overend TJ. Maximal aerobic capacity testing of older adults: a critical review. J Gerontol A Biol Sci Med Sci. 2005;60(1):57-66.

18. Kang S, Hwang S, Klein AB, Kim SH. Multicomponent exercise for physical fitness of community-dwelling elderly women. $J$ Phys Ther Sci. 2015;27(3):911-5.

19. Kloubec JA. Pilates for improvement of muscle endurance, flexibility, balance, and posture. J Strength Cond Res. 2010;24(3):661-7.

20. Kuipers H, Verstappen FT, Keizer HA, Geurten P, van Kranenburg G. Variability of aerobic performance in the laboratory and its physiologic correlates. Int J Sports Med. 1985;6(4):197-201.

21. Larish DD, Martin PE, Mungiole M. Characteristic patterns of gait in the healthy old. Ann N Y Acad Sci. 1988;515:18-32.

22. Liou YM, Lee HL, Chien LY, Kao WY, Chiang CC, Wang DY. Daily-life physical activity and related factors among patients with cancer receiving chemotherapy in Taiwan. Cancer Nurs. 2011;34(6): 443-52.

23. Makizako H, Shimada H, Doi T, et al. Cognitive functioning and walking speed in older adults as predictors of limitations in selfreported instrumental activity of daily living: prospective findings from the Obu Study of Health Promotion for the Elderly. Int $J$ Environ Res Public Health. 2015;12(3):3002-13.

24. Martin PE, Rothstein DE, Larish DD. Effects of age and physical activity status on the speed-aerobic demand relationship of walking. J Appl Physiol (1985). 1992;73(1):200-6.

25. Meijer EP, Westerterp KR, Verstappen FT. Effect of exercise training on physical activity and substrate utilization in the elderly. Int J Sports Med. 2000;21(7):499-504.

26. Mian OS, Thom JM, Ardigò LP, Morse CI, Narici MV, Minetti AE. Effect of a 12-month physical conditioning programme on the metabolic cost of walking in healthy older adults. Eur J Appl Physiol. 2007;100(5):499-505.

27. Mian OS, Thom JM, Ardigo LP, Narici MV, Minetti AE. Metabolic cost, mechanical work, and efficiency during walking in young and older men. Acta Physiol (Oxf). 2006;186(2):127-39.

28. Middleton A, Fritz SL, Lusardi M. Walking speed: the functional vital sign. J Aging Phys Act. 2015;23(2):314-22.

29. Morley JE, Anker SD, von Haehling S. Prevalence, incidence, and clinical impact of sarcopenia: facts, numbers, and epidemiologyupdate 2014. J Cachexia Sarcopenia Muscle. 2014;5(4):253-9.

30. Norris JA, Granata KP, Mitros MR, Byrne EM, Marsh AP. Effect of augmented plantarflexion power on preferred walking speed and economy in young and older adults. Gait Posture. 2007;25(4):620-7.

31. Ortega JD, Farley CT. Individual limb work does not explain the greater metabolic cost of walking in elderly adults. J Appl Physiol (1985). 2007;102(6):2266-73.

32. Peterson DS, Martin PE. Effects of age and walking speed on coactivation and cost of walking in healthy adults. Gait Posture. 2010;31(3):355-9.
33. Phu S, Boersma D, Duque G. Exercise and sarcopenia. J Clin Densitom. 2015;18(4):488-92.

34. Poehlman ET, Danforth E Jr. Endurance training increases metabolic rate and norepinephrine appearance rate in older individuals. Am J Physiol. 1991;261(2 Pt 1):E233-9.

35. Ralston HJ. Energy-speed relation and optimal speed during level walking. Int Z Angew Physiol. 1958;17(4):277-83.

36. Romero-Arenas S, Martínez-Pascual M, Alcaraz PE. Impact of resistance circuit training on neuromuscular, cardiorespiratory and body composition adaptations in the elderly. Aging Dis. 2013;4(5): 256-63.

37. Rosenberg IH. Sarcopenia: origins and clinical relevance. Clin Geriatr Med. 2011;27(3):337-9.

38. Schrack JA, Simonsick EM, Chaves PH, Ferrucci L. The role of energetic cost in the age-related slowing of gait speed. $J \mathrm{Am}$ Geriatr Soc. 2012;60(10):1811-6.

39. Schrack JA, Simonsick EM, Ferrucci L. The energetic pathway to mobility loss: an emerging new framework for longitudinal studies on aging. J Am Geriatr Soc. 2010;58(2 Suppl):S329-36.

40. Simonsen EB. Contributions to the understanding of gait control. Dan Med J. 2014;61(4):B4823.

41. Sola K, Brekke N, Brekke M. An activity-based intervention for obese and physically inactive children organized in primary care: feasibility and impact on fitness and BMI: a one-year follow-up study. Scand J Prim Health Care. 2010;28(4):199-204.

42. Speakman JR, Westerterp KR. Associations between energy demands, physical activity, and body composition in adult humans between 18 and 96 y of age. Am J Clin Nutr. 2010;92(4):826-34.

43. Steinhaus LA, Dustman RE, Ruhling RO, et al. Aerobic capacity of older adults: a training study. J Sports Med Phys Fitness. 1990;30(2):163-72.

44. Thomas DM, Bouchard C, Church T, et al. Why do individuals not lose more weight from an exercise intervention at a defined dose? An energy balance analysis. Obes Rev. 2012;13(10):835-47.

45. Valenti G, Bonomi AG, Westerterp KR. Body acceleration as indicator for walking economy in an ageing population. PLoS One. 2015;10(10):e0141431.

46. VanSwearingen JM, Perera S, Brach JS, Cham R, Rosano C, Studenski SA. A randomized trial of two forms of therapeutic activity to improve walking: effect on the energy cost of walking. J Gerontol A Biol Sci Med Sci. 2009;64(11):1190-8.

47. VanSwearingen JM, Studenski SA. Aging, motor skill, and the energy cost of walking: implications for the prevention and treatment of mobility decline in older persons. J Gerontol A Biol Sci Med Sci. 2014;69(11):1429-36.

48. Waters RL, Hislop HJ, Perry J, Thomas L, Campbell J. Comparative cost of walking in young and old adults. J Orthop Res. 1983;1(1):73-6.

49. Wert DM, Brach JS, Perera S, VanSwearingen J. The association between energy cost of walking and physical function in older adults. Arch Gerontol Geriatr. 2013;57(2):198-203.

50. Westerterp KR. Alterations in energy balance with exercise. Am J Clin Nutr. 1998;68(4):970S-4.

51. Westerterp KR, Meijer EP. Physical activity and parameters of aging: a physiological perspective. J Gerontol A Biol Sci Med Sci. 2001;56(Spec No 2):7-12.

52. Westerterp KR, Meijer GA, Janssen EM, Saris WH, Ten Hoor F. Long-term effect of physical activity on energy balance and body composition. Br J Nutr. 1992;68(1):21-30.

53. Westerterp KR, Wouters L, van Marken Lichtenbelt WD. The Maastricht protocol for the measurement of body composition and energy expenditure with labeled water. Obes Res. 1995;3(1 Suppl): $49-57$.

54. Westerterp-Plantenga MS, Fredrix EWHM, Steffens AB. Food intake and energy expenditure. Boca Raton: CRC Press; 1994. p. 408. 